\title{
Influence of Dynamic Capabilities in Creating Disruptive Innovation
}

\author{
Rūta Čiutiené ${ }^{1}$, Emil William Thattakath ${ }^{2},{ }^{1,2}$ Kaunas University of Technology
}

\begin{abstract}
The aim of this paper is to demonstrate the influence of Dynamic Capabilities in creating Disruptive Innovation. For doing so the concepts of Dynamic Capabilities and Disruptive Innovation are reviewed. The criteria of an innovation named Disruptive Innovation are obtained by comparative study between the various innovation types. To demonstrate the role of Dynamic Capabilities in creating Disruptive Innovation, the Innovation Lifecycle is demonstrated with respect to Dynamic Capabilities. The advantages obtained from Disruptive Innovation and its superiority in comparison with other types of innovation are also portrayed. Suitable examples and case studies are presented to describe certain situations. This paper establishes the required clarification by using comparative methodology for obtaining the results.
\end{abstract}

Keywords - Dynamic Capabilities, Disruptive Innovation, Innovation Lifecycle.

\section{INTRODUCTION}

In today's world innovative companies constantly face challenges from their respective environments. These challenges or competitions includes hyper-competition, governmental regulation, recession, deregulation or even disruptive innovation [1]. In addition, these innovative companies are forced to follow the agenda asking them to be sustainable and environmental friendly. In the midst of all this every innovative company wants to maintain a healthy competitive advantage in the market. To maintain this competitive advantage, a strong requirement is seen to develop the dynamic capabilities - essentially those adaptive capabilities that enable an organisation to develop new capabilities better fitted to the changing environment [1].

Most of the literature on technological innovation points to established companies as victims of disruptive innovation, one of the most influential streams in the strategy literature today has developed the idea of dynamic capabilities which enables established companies to thrive [2]. In the meantime, while most of the innovative companies are thriving to create this disruptive innovation in their market (as Christensen quotes: "Motivation is the catalysing ingredient for every successful innovation. The same is true for learning."'[3]), how to maintain a competitive advantage while doing so, is quite a difficult question to answer. As seen from the past cases, for example, Ford's introduction of automobile into the market using disruptive innovation was a success while Kodak's story in digital photography was a failure although they were the inventors of this. This article is mainly going to show that by enhancing the dynamic capabilities of the innovative company, maintaining of Disruptive Innovation to its advantage is possible. The article will portray the literature review of both dynamic capabilities, disruption innovation and finally, how they could work together in particular situations with the help of case studies. In addition to that the discussion of a linear progression of different types of innovation with respect to a firm and the differences between the types of innovation in comparison with Disruptive Innovation along with the Dynamic Capabilities applied is demonstrated. The discussion of the main concept, features and the role of Dynamic Capability in a company and its advantages is demonstrated. The criteria and advantages of Disruptive Innovation are also discussed.

\section{DYNAMIC CAPABILITIES}

It was primarily introduced by Gary Hamel in 1989 who demonstrated the multinational strategic research leading to Core Competences of the Corporation [4], although shortly after, in 1995, it was described by Ikujiro Nonaka and Hirotaka Takeuchi in their book on innovation strategy "The Knowledge-Creating Company" [5]. Finally, dynamic capability was referred to as "the capacity of an organization to purposefully create, extend, or modify its resource base" by Helfat [6]. Although in [7] it is explained that the capacity to renew competences so as to achieve congruence with the changing business environment is Dynamic Capability too. This involves strategic management in appropriately adapting, integrating, and reconfiguring internal and external organizational drawbacks, resources, and functional competences to match the requirements of the changing environment. In line with Helfat [6] we use the term ,resource ${ }^{\text {ee }}$ in its broad sense as in [8], and hence it includes activities, capabilities, etc., which allow the firm to generate the rent.

So, essentially looking at resource based view (RBV) in the company's perspective, Daneels [9] concludes that to understand how a firm evolves over time the dynamic RBV is kind of essential. In this case the firm over time tries to continuously renew and reconfigure itself to survive in the market while deploying its available resources.

Dynamic Capabilities are built rather than being bought in the market [10]. They mainly consist of organizational process or routines [6], [11] which were imbibed by the firm over time and consequently used to reconfigure the firm's resource base by removing decaying resources or by recombining old resources with new ones using new methods or ways [12].

This thereby shows that Dynamic Capabilities are viewed in accordance with the path taken [13]. This path is shaped by the decisions the firm has made in the past and the stock of assets it holds currently [11]. Path dependency "not only defines what choices are open to the firm today, but also puts 
bounds around what its internal repertoire is likely to be in the future" [14]. Path dependency could be grounded in knowledge, resources familiar to the firm, or influenced by the social and collective nature of learning [14]. Learning plays an important role in creation and development of Dynamic Capabilities. Zollo and Winter [11] demonstrate that learning is the base of dynamic capabilities and guides their evolution. Learning is also considered as a dynamic capability itself, rather than an antecedent of it. As such, learning as a dynamic capability has been identified as "a process by which repetition and experimentation enable tasks to be performed better and quicker" [14]. In Zollo and Winter [11] authors attempted to meld these two positions by explaining that "dynamic capabilities are shaped by the co-evolution of learning mechanisms".

Helfat and Peteraf [15] emphasise that to qualify as a dynamic capability, the capability not only needs to change the resource base, but it also needs to be embedded in the firm, and ultimately be repeatable. Dynamic capabilities are argued to comprise four main processes: reconfiguration, leveraging, learning and integration [14]. Reconfiguration refers to the transformation and recombination of assets and resources, e.g., the consolidation of manufacturing resources that often occurs as a result of an acquisition [25]. Leveraging refers to the replication of a process or system that is operating in one area of a firm into another area, or extending a resource by deploying it into a new domain [25], for instance, applying an existing brand to a new set of products. As a dynamic capability, learning allows tasks to be performed more effectively and efficiently, often as an outcome of experimentation, and permits reflection on failure and success. Finally, integration refers to the ability of the firm to integrate and coordinate its assets and resources, resulting in the emergence of a new resource base.

In accordance with the explanation of Dynamic Capabilities they are referred to as the ability of the firm to purposefully create, extend, or modify its resource base in congruence with the changing business environment. In relation to this, the aspect that has been discovered is, that there is a change in the business environment and to obtain this competitive advantage in the respective market Dynamic Capabilities are deployed. But this can also be used to create an altogether new business environment where this company holds the advantage due to its core competence which is difficult to be duplicated by its competitors. One of the successful and feasible methods to do so is introducing Disruptive Innovation which can be managed and created with the help of Dynamic Capabilities. This will be demonstrated shortly in this article where some of the analysed examples show how the obtained result can be achieved.

\section{DISRUPTIVE INNOVATION}

\section{A. Concept of Disruptive Innovation}

Disruptive Innovation was primarily introduced by Christensen [16] where he defines it as "a process by which a product or service takes root initially in simple applications at the bottom of a market and then relentlessly moves up market, eventually displacing established competitors." Disruptive technology predates the term disruptive innovation. Christensen changed the term to disruptive innovation so that it would include services as well as products. Often in literature the terms are used interchangeably. Despite the widespread use of both terms by Christensen and other academics, there is still some ambiguity surrounding the definition of disruptive innovation.

One of the major flaws in Christensen's primary model was discovered by Tellis in [17]. He justifies that Christensen's definition lacks measurability and has little predictive value. Christensen's theory states that "Disruptive Technologies Displace Incumbent Technologies", but that is something which can only be ascertained with hindsight. In today's market, most of the innovative companies harness technologists and technology developers who would want to assess the technology that they are currently working on has the ability to become a Disruptive Innovation in the future. Developers and marketers need to be aware of the disruptiveness of their technologies in order to be able to tailor their strategy around it. Market leaders also need to know when technologies are disruptive as they pose a great threat to their business model. Consequently, in relation to this Danneels in [18] agrees that this lack of knowledge has to be solved, and answers the question related to the assessing an innovation of its disruptiveness. As a result Danneels puts forward a complementing definition for Disruptive innovation. He states that "a disruptive technology is a technology that changes the bases of competition by changing the performance metrics along which firms compete". Although this literature tries to solve this lapse it has not been completely done. The most recent study was carried out by Gilbert in [19] who defines Disruptive innovation as "a new technology that unexpectedly displaces an established one". The superiority of Gilbert's study and definition is presented as it highlights one particular factor about what makes a technology disruptive; the often-unexpected nature of the disruption and the fact that established technologies are affected. But it still is missing some key factors and it does not allow us to determine if a new technology is likely to become a disruptive technology. Again, it only really allows us to decide if a technology has been disruptive after the disruption has occurred in the market place. And it does not deal with the level of disruption. 
As the criteria for an innovation to qualify as disruptive are not clearly demonstrated it is hard to set goals or a strategy to create one. As in further development of this paper it will be demonstrated how Disruptive Innovation can be advantageous to a company and it will be done by comparing the different kinds of innovation including Incremental Innovation, Radical Innovation, and Breakthrough Innovation to Disruptive Innovation.

\section{B. Comparison between the Different Types of Innovation and Disruptive Innovation}

Innovation as a whole has a very wide view and to make it concise and express into assessable figures has been quite a task. When considering it, different approaches to innovation had been applied. Normally, to demonstrate an innovation the most efficient method was to distinguish it among the different types of innovation. Many of the innovations are distinguished between the two extremes, they view innovation on dichotomous scale. For instance, Michael Porter [20] talks about "continuous" and "discontinuous" technological changes; Tushman and Anderson [21] distinguish between "incremental" and "breakthrough" innovation; Abernathy and Clark refer [22] to "conservative" vs. "radical" innovations; and Clayton Christensen [16] shows the difference between "sustaining" and "disruptive" innovations. This helps to differentiate types of innovation efforts but while viewing innovation in one dimension [23] an effective demonstration is missing.

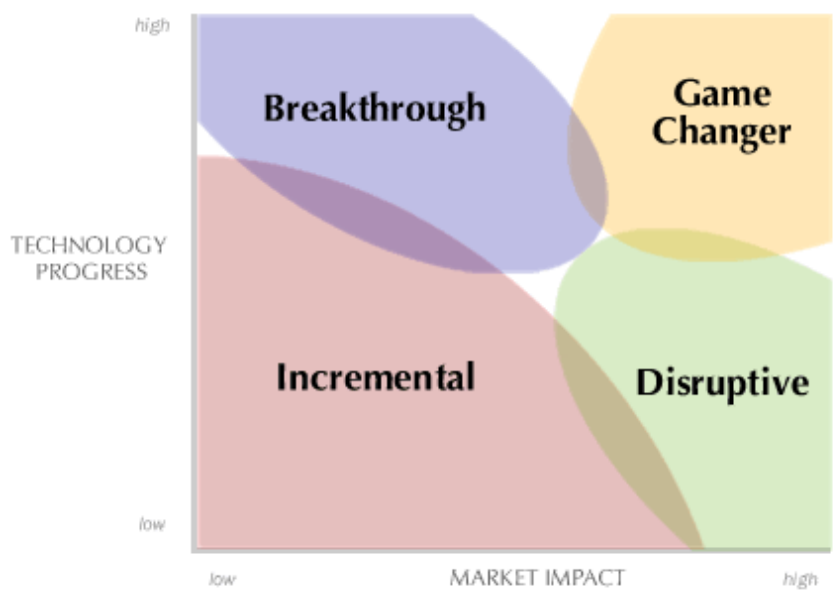

Fig. 1. Two-dimensional picture of innovation [23].

James Kalbach [23] has an explanation for this certain case. He demonstrates innovation with respect to a two dimensional scale which shows the comparison between the different kinds of innovation.

The $y$-axis indicates the degree of technological progress an innovation brings with it. Moving from low to high along this line indicates improving existing capabilities, services and products. The $x$-axis shows the impact an innovation has on the market, also from low to high. This usually entails new business models or reaching underserved target groups [23].

In Fig. 1, distinctly four zones of innovation can be seen. The zones consist of Incremental Innovation, Breakthrough Innovation, Game Changer or Radical Innovation and finally Disruptive Innovation.
Incremental innovation involves modest changes to existing products and services. These are enhancements that keep a business competitive, such as new product features and service improvements [23]. One of the most successful and recent examples of incremental innovation is the iPhone. While smartphones existed before Apple entered the market, it was mostly the incremental innovation of a larger touchscreen, the App store, ease of use and an improved overall experience, which enabled the iPhone to be the first in making smartphones mainstream. Apple then created a whole new ecosystem which made the iPhone a preferred medium for accessing the internet, sending e-mail, finding directions, playing games, conducting online transactions and generally becoming a central part of our daily lives. In 2013, it shipped 125 million iPhones. It is Incremental Innovation which has brought a fundamental change in our behaviour and created a market that will be worth $\$ 1.6$ trillion by 2018 [27]. Although Incremental Innovation has its inherent advantages, slowness to reach growth targets before competitors, leading to a loss of competitive advantage is considered to be its biggest disadvantage. Incremental Innovation also falls under the sphere of Sustaining Innovation. Sustainable Innovation does not create new markets or value networks but rather only evolves existing ones with better value, allowing the firms within to compete against each other's sustaining improvements. Sustaining Innovation may be also "discontinuous" [16].

Breakthrough Innovation refers to large technological advances that propel an existing product or service ahead of competitors. This is often the result of research and development labs (R\&D), who are striving for the next patentable formula, device and technology [23]. These technologies originate on the supply side of supply chain. Conventional wisdom says-listen to the market, but breakthroughs come from labs that do not have what the customer wants. These technologies are then pushed onto the consumer. For example, Tim Berners-Lee, a software engineer, created a network of interconnected computers to share and distribute information easily and cheap in 1980. This network developed into the Internet. Berners-Lee never thought about what customers wanted when he created his network. The interaction between research, marketing and development groups can be detrimental. In general, most marketing professionals view marketing as getting a grasp of what customers need. They do not put emphasis on educating customers about the usefulness of technology or creating a new market. Therefore, R\&D groups must make a marketing group understand how useful the technology will be. R\&D groups must be visionary and lead the other groups in productizing the technology. R\&D groups should encourage marketing groups to seek new markets for the developed technology.

Game-changing/Radical Innovation transforms markets and even society. This innovation has a radical impact on how humans act, think and feel [23]. One of the most prominent examples is Amazon's internet based approach to selling books which enabled it to offer many more books than a traditional bookstore, this ultimately led to a number of the 
$2014 / 26$

traditional book stores going out of business. As of 2010, Amazon was the largest online retailer in the US [28]. The biggest disadvantage of Radical Innovation is that the cost of introducing this innovation into the market is very high, in addition there is always a risk of low adoption rate of the technology which can backfire to any company [28].

In reality there is a thin line between Radical Innovation and Disruptive Innovation. This can be explained through an example of Disruptive Innovation. The automobile was a revolutionary innovation but it was not disrupting the horse drawn carts industry in the very beginning. Later on the automobiles became a luxury commodity for elite public. When the idea of mass production of automobiles was introduced by Ford in 1909, the mass production of cars disrupted the horse drawn carts industry as this car now was affordable to a lot more people. The main difference between Radical and Disruptive Innovation is that a Radical Innovation might not disrupt an existing market as the innovation might be too expensive to be approached. On the other hand Disruptive Innovation does not need to be based on a technological innovation, for example, Microfinance did not involve radically new technology.

Based on the literature review, it can be concluded that the advantages of Disruptive Innovation over the other types of innovation are:

- In relation to Incremental Innovation, Disruptive Innovation is at an advantage with respect to an entry level company. Incremental Innovation mainly delivers results to a company which has been established over some time being an incumbent in that innovation, while trying to modify their innovation at a certain pace. But this technique cannot be used to attain a complete advantage by an entrant, while it can use Disruptive Innovation to achieve nearly the same goals as an incumbent establishment.

- In relation to Breakthrough and Radical Innovation, as Disruptive innovation was or might have been a Radical or Breakthrough Innovation to begin with it would have been available to an elite class of customers in the beginning. But once that particular technology starts getting cheaper it is able to reach majority of customers by dispersing the existing innovation. In this case the company yields more as it lowers its risk of low adoption rate and ensures stable income.

\section{USING DYNAMIC CAPABILITIES TO CREATE DISRUPTIVE INNOVATION}

Here the description of how Dynamic Capabilities can be used to create a Disruptive Innovation will be discussed. As it was presented earlier, a firm following Disruptive Innovation obtains higher gain as compared to using alternative innovations. Meanwhile, there is a very small difference between different kinds of the demonstrated innovation types and in many cases the shift between these innovation types is observed within a company. These shifts between the different innovation types can be keyed together and form the Innovation Lifecycle. Dynamic Capabilities play major role in these shifts and overall linking of the Innovation Lifecycle. To view how Dynamic Capabilities actually affect Disruptive Innovation, the concept of Innovation Lifecycle will be presented.

The description of the Innovation Lifecycle will be made with respect to the theoretical analysis in addition to having an evolution of a concept. Fig. 2 is a stepwise presentation of a possible scenario that can occur to an innovative company in the event when it created a new technology and thereby put it to the market. Meanwhile, in accordance with the management and innovation strategy of the company it can directly lead to any of the steps and consequently following the Innovation Lifecycle. In this explanation, the description of a common example with relation to the Innovation Lifecycle will be given. For demonstration purposes the example of introduction of automobiles will be illustrated.

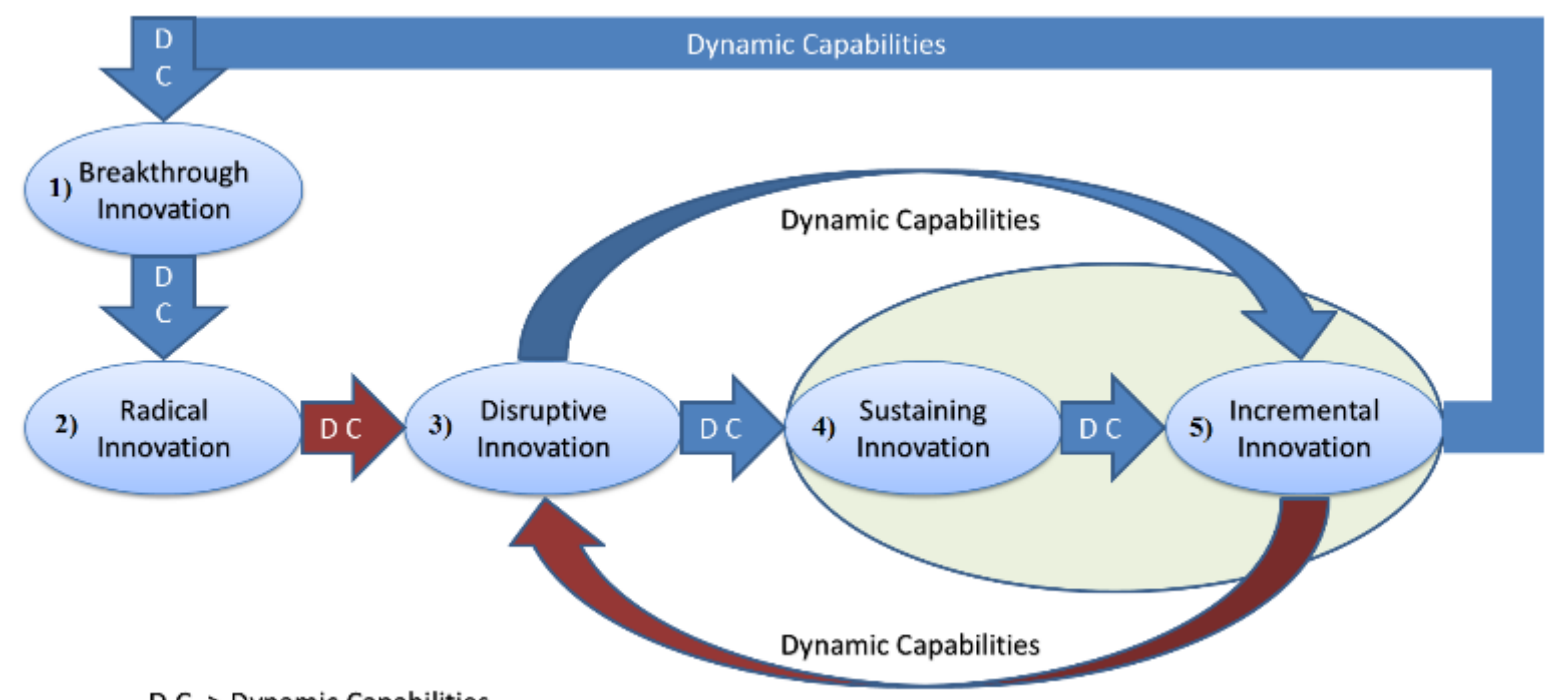

D C -> Dynamic Capabilities

Fig. 2. Innovation Lifecycle with respect to Dynamic Capabilities. 
In 1807 , the invention of the internal combustion engine coupled with a vehicle design by François Isaac de Rivaz was a prominent innovation [24]. Although this was quite a fascinating innovation, it did not directly hit the market as people were at that time quite satisfied with the animal drawn carts. This situation directly correlates with the first stage in Fig. 2 which is the "Breakthrough Innovation". The low absorption rate of the innovation as well as the small performance gap between the already available alternative lets down this innovation in the market to begin with. As time went by, application of Dynamic Capabilities occurred in the technological perspective and by 1886 Benz PatentMotorwagen, by Karl Benz [24] car was regarded as the birth of the modern automobile. The capabilities required here in this situation were the Dynamic Capabilities to find efficient solution and advanced product that could outrun the current market. This, with respect to Fig. 2 represents the second stage which is called "Radical Innovation". The problem at this stage is that, although the technology has an impact on the market, because of the high price and scarcity of the product this technology does not reach the majority of the public. In our case the automobile was only available to an elite level of customers who would not mind to purchase expensive products. In 1908 the Ford T model was introduced. This time Ford came up with the plan and criteria of the mass production of vehicles. Through purposefully creating, extending and modifying its resource base in accordance with the technology and market, Ford was able to make automobiles cheaper and more affordable to general public. In doing so the existing market for animal driven carts were disrupted by the mass produced automobiles. Ford was able to maintain a competitive advantage in the market efficiently and got lot of returns from a large population of customers purchasing their vehicle. This represents the third stage in Fig. 2 which is "Disruptive Innovation". As time went by, the mass production technique for automobiles was absorbed by many other companies in relative competition with Ford and at this stage, although Ford was still mass producing, the vehicle competition was high. The amount of returns generated reduced and they just started sustaining in the market. This represents the fourth stage of Fig. 2 which is "Sustaining Innovation". Although Dynamic Capabilities were applied to reach a comfortable income generating level, the competition in the market devoid Ford to achieve as much as when its innovation was a Dispersive Innovation. So, while it tried to survive in the market, slight technological improvements to the initial design were created in order to stay ahead in competition. The engine design as well as the architecture of the vehicle were changed. In addition to that managerial innovation was introduced to efficiently maintain competitive advantage. This level represents the fifth stage in Fig. 2 which is "Incremental Innovation". There is no assurity as to how long the company can thrive in the market before a competitor introduces a Dispersive Innovation and topples all gains altogether. For example, Toyota emerged victorious in the automobile battle when it introduced Dynamic Capabilities in its supply chain mechanism there by introducing "just in time" the mechanism to ensure higher quality as well as higher production rate. The final step that happens is the creation of a Breakthrough Innovation with the help of Dynamic Capabilities of existing companies or borrowing an existing Breakthrough Innovation and using it in their product design. This example can be portrayed in introducing vehicles run by fuel cells. Although the first modern fuel cell vehicle was a modified Allis-Chalmers farm tractor in 1959, it was developed and used by its inventor - NASA, for powering rockets. The first demonstration of the fuel cell car was made by General Motors in 1966 and thereafter many vehicle companies have tried to introduce commercial vehicles with this technology. Currently this technology resides in the second stage of Fig. 2 which is the Radical Innovation stage as this technology is quite expensive for general public to utilise, as well as the alternative fuel sources are still quite efficient with respect to a common man use. In the near future the expectation to build on the Dynamic Capabilities in the organisation to create a Disruptive Innovation out of the fuel cell technology is being aimed at.

While the whole Innovation Lifecycle proceeds, there is an interesting relationship between Disruptive Innovation and Incremental Innovation. Dr. Sarah E. A. Dixon [1] demonstrates a Dynamic Capabilities Lifecycle. She demonstrated the need for Dynamic Capabilities in adapting market by presenting the case study of Toyota failing to adapt in accordance with their deployment of capabilities over wide geographic regions, and how EMI record label failed to cope with the online music downloading trend with their audio CDs which were way more expensive than the music downloads. By this she explained that market turbulence affects all companies in that market equally. She also pointed out that successful companies combine the constant honing of their existing capabilities to achieve operational excellence at the same time as developing new capabilities with a better fit to a continually evolving environment. Those new capabilities may be associated with product innovation or management innovation; with new market offerings or new business models [1].

As pointed out in Fig. 2, there is a Dynamic Capabilities cycle between Incremental Innovation and Disruptive Innovation. Dr. Sarah E A Dixon explains that this shift between the innovations determines the firm's failure, survival or success. She demonstrates that to attain a Disruptive Innovation is at an advantage in comparison to having an Incremental Innovation strategy.

From the analysis in the Fig. 2 it can be seen that as Disruptive Innovation is advantageous for a company, in order to maintain it is important for Dynamic Capabilities to be refined in the areas which direct to Disruptive Innovation. As indicated in Fig. 2 in red, without developing and implying Dynamic Capabilities, Disruptive Innovation cannot be achieved. Because of this close difference between the stages in the innovation, Dynamic Capabilities play major role in maintaining the shift between the various innovations and finally directing towards Disruptive Innovation. The example of failure of Kodak when they confronted the arrival of digital photography was analysed. Kodak did not ignore digital 
photography, it can even be said that they invented it as the first prototype of digital camera which was finalised by a Kodak engineer (Steven Sasson) in December 1975. This camera weighted $3.6 \mathrm{~kg}$, its picture definition was $100 \times 100$ pixels, and storing of the image was done on an audio tape, a process which took 23 seconds per picture; overall a good example of a disrupting technology with lower performance during its initial stages. Kodak did not ignore digital photography in the subsequent years either; it launched several professional digital cameras in 1990 and 1991 (one of them, the Kodak DSC-100, had a 1.3 megapixel definition and carried a price tag of $\$ 13000$ ) and a consumer-level camera in 1995 (Kodak DC40, which could be connected to a PC via a serial cable). By the mid-1990s, digital photography was clearly gaining ground; JPEG and MPEG formats had been created in 1988, and several companies had launched digital cameras. But rather than going full steam for digital photography, Kodak, along with a few other major players of the industry (including Fujifilm, Minolta, Nikon and Canon) chose to launch a new system based on a digital film - APS (Advanced Photo System, launched in 1996). In 1999, Nikon introduced the Nikon D1 - a 2.74 megapixel camera at a cost of under $\$ 6,000$, a price some professional photographers and high-end consumers could afford. There were also a full range of more affordable cameras already available for sale in Japan (in the $\$ 500$ to $\$ 1000$ range). In 2000 , at a time it was becoming clearer that digital photography would prevail thanks to improving technical performances and lower prices, Kodak was still promoting the APS (including during the Sidney Olympic Games). But finally Kodak had to seize the production of APS and finally failed in the photo market. Digital photography was a Disruptive Innovation and the lack of modifying its management techniques and implying Dynamic Capabilities Kodak would have been capable to shine in the turbulent market. Had it concentrated more on the new technology which is digital photography other than being an incumbent in the digital film by applying Dynamic Capabilities, it had a possibility to still conquer the market.

As a result innovative companies would be at an advantage laying their strategies to enhance their Dynamic Capabilities directing to Disruptive Innovation (Fig. 2, red arrows). To have a Radical Innovation transformed into a Disruptive Innovation certain capabilities need to be refreshed and dynamized. The particular Radical Innovation should become cheaper and more available to a bigger circle of customers as a result that innovation would compete with the currently available alternative innovation. As it was a Radical Innovation to begin with that particular innovation would have some inherent advantages, because of the added availability and lowered prices this innovation disrupts the competition, innovation thereby transforming into a Disruption Innovation. In order to efficiently execute this transformation the firm constituted of that Radical Innovation should purposefully create, extend, or modify its resource base in congruence with the changing business environment. As demonstrated earlier in this paper the mass production of automobiles is the best example.
To have Incremental Innovation to be converted to a Disruptive Innovation involves exploration of ideas and new path creation, for example the redesign of the business model or the invention of new products. This requires a combination of organisational slack (availability of time and resources to be allocated to things other than the day-to-day business operations) and absorptive capacity (the ability to conceptualise new ways of doing things, to understand the changing environment and to be open to new ideas to acquire new knowledge and think in new ways) [1]. Here the focus on creativity and exploration for new ideas and on the utilisation of these new ideas to create new developmental paths for the organisation is given most importance [1]. For example Google creates an organisational climate that is conducive to exploring new ideas, at the same time having processes for turning those ideas into practical user propositions that help to reinvent their business [1].

\section{CONCLUSION}

Before commencing conclusions a few areas for future research will be highlighted. As noted by multiple authors, the challenge of conceptual research is to develop empirical measures. The next possible step for this research is to carry out the empirical study on the demonstrated contents. The proposal to observe the working and implication of Dynamic Capabilities for Disruptive Innovation to arise in a company should be carried out. The analysis of the level of difficulty of applying Dynamic Capabilities to achieve Disruptive Innovation should be assessed in real time. After this the discussion should be carried out based on the results.

In conclusion the description of Dynamic Capabilities was presented as the ability of the firm to purposefully create, extend, or modify its resource base in congruence with the changing business environment. It was also discussed that Dynamic Capabilities can not only be used to cope with the changing business environment but also to introduce change in the particular environment.

The main concept and criteria of Disruptive Innovation were discussed. It was concluded that the exact criteria for an innovation to qualify as disruptive is not clearly demonstrated in accordance with previous literature, as a result it is hard to set goals or a strategy to create one. To counter that the comparative study between the different innovation types is given to obtain distinguished criteria for Disruptive Innovation. The demonstration of innovation with respect to a two dimensional scale which shows the comparison between the different kinds of innovation is made in accordance with concept portrayal and examples. The advantage of Disruptive Innovation over the other innovation types is made.

Finally the demonstration of the Innovation Lifecycle is carried out where the example of the evolution of the automobile industry is given. The use of Dynamic Capabilities to achieve each of the innovation types is demonstrated and the Dynamic Capabilities which are used to achieve a Disruptive Innovation have been highlighted by suitable examples. It is thereby seen that a company implying Disruptive Innovation in their respective market is at 
advantage and the Dynamic Capabilities are inevitable to function in a company that wants to achieve Disruptive Innovation.

\section{REFERENCES}

[1] Professor and Dean of Xi'an Jiaotong Liverpool University Business School in Suzhou, China, Dr. Sarah E. A. Dixon, "Failure, Survival or Success in a Turbulent Environment: The Dynamic Capabilities Lifecycle," Management Articles of the Year January, 2013. [Accessed 25.05.2014]

[2] Bernard, B., "Incumbent Curse or Incumbent Capabilities?" Solvay Brussels School of Economics and Management, 2013. [Accessed 27.06.2014].

[3] Christensen, C. M., Horn, M. B. and Johnson, C. W., "Disrupting Class: How Disruptive Innovation Will Change the Way the World Learns," New York: McGraw-Hill, 2008.

[4] Prahalad, C. K. and Hamel, G., "The Core Competences of the Corporation," Harvard Business Review. May 1990.

[5] Nonaka, I. and Takeuchi, H., "The Knowledge-Creating Company: How Japanese Companies Create the Dynamics of Innovation," Oxford University Press, 1995.

[6] Helfat, C. E., "Dynamic Capabilities: Understanding Strategic Change in Organizations," Malden, MA: Blackwell Pub., 2007.

[7] Teece, D. J., Pisano, G. and Shuen, A., "Dynamic Capabilities and Strategic Management," Berkeley: U of California, 1992.

[8] Barney, J., "Firm Resources and Sustained Competitive Advantage," Journal of Management vol. 17, no. 1, 1991, pp. 99-120. Web. [Accessed: 12.06.2014]. http://dx.doi.org/10.1177/014920639101700108

[9] Danneels, E., "The Dynamics of Product Innovation and Firm Competences," Strategic Management Journal vol. 23, no. 12, 2002, pp. 1095-1121. [Accessed: 05.06.2014]. http://dx.doi.org/10.1002/smj.275

[10] Makadok, R., "Toward a Synthesis of the Resource-based and Dynamiccapability Views of Rent Creation," Strategic Management Journal vol. 22, no. 5, 2001, pp. 387-401. [Accessed: 15.06.2014]. http://dx.doi.org/10.1002/smj.158

[11] Zollo, M. and Winter, S. G., "Deliberate Learning and the Evolution of Dynamic Capabilities," Organization Science vol. 13, no. 3, 2002 pp. 339-351. [Accessed: 25.05.2014]. http://dx.doi.org/10.1287/orsc.13.3.339.2780

[12] Ireland, R. D., Hitt, M. A. and Sirmon, D. G., "A Model of Strategic Entrepreneurship: The Construct and Its Dimensions," Journal of Management vol. 29, no. 6, 2003, pp. 963-989. [Accessed 07.06.2014].

[13] Dierickx, I. and Cool, K., "Asset Stock Accumulation and Sustainability of Competitive Advantage," Management Science vol. 35, no. 12, 1989 , pp. 1504 - 1511. [Accessed: 04.06.2014]. http://dx.doi.org/10.1287/mnsc.35.12.1504

[14] Teece, D. J., Pisano, G. and Shuen, A., "Dynamic Capabilities and Strategic Management," Strategic Management Journal vol. 18, no. 7, 1997, pp. 509-533. [Accessed: 01.06.2014]. http://dx.doi.org/10.1002/(SICI)1097-0266(199708)18:7<509::AIDSMJ882>3.0.CO;2-Z

[15] Helfat, C. E. and Peteraf, M. A., "The Dynamic Resource-based View: Capability Lifecycles," Strategic Management Journal vol. 24, no. 10, 2003 , pp. 997-1010. [Accessed: 02.06.2014]. http://dx.doi.org/10.1002/smj.332
[16] Bower, J., Christensen, C., "Disruptive technologies," Catching the wave. Harv Bus Rev, 1995, pp. 43-53.

[17] Tellis, G. J., "Disruptive technology or visionary leadership?" J. Prod. Innov. Manag., vol. 23, no. 1, 2006, pp. 34-38. http://dx.doi.org/10.1111/j.1540-5885.2005.00179.x

[18] Danneels, E., "Disruptive technology reconsidered - a critique and research agenda," Prod Dev Manag Assoc 2004, vol. 21, pp. 246-258.

[19] Gilbert, J. B., Confronting disruptive innovation; 2013. pp. 280-2.

[20] Porter, M. E., "Technology and Competitive Advantage," Journal of Business Strategy, vol. 5, no. 3, 1985, pp. 60-78. [Accessed: 05.06.2014]. http://dx.doi.org/10.1108/eb039075

[21] Anderson, P. and Tushman, M. L., "Technological Discontinuities and Dominant Designs: A Cyclical Model of Technological Change," Administrative Science Quarterly vol. 35, no. 4, 1990, pp. 604-633. [Accessed 11.06.2014].

[22] Abernathy, W. and Kimb, C. "Innovation: Mapping the Winds of Creative Destruction," Research Policy, vol. 22, no. 2, 1993, p. 102. [Accessed: 09.06.2014].

[23] Kalbach, J., "Clarifying Innovation: Four Zones of Innovation," Experiencing Information. [Accessed: 10.06.2014].

[24] Eckermann, E., "World History of the Automobile'. SAE Press, 2001, p. 14. http://dx.doi.org/10.4271/R-272

[25] Ambrosini, V., Bowman, C. and Schoenberg, R., "Should Acquiring Firms Pursue More Than One Value Creation Strategy? An Empirical Test of Acquisition Performance," British Journal of Management vol. 22, no. 1, 2011, pp. 173-185. [Accessed: 13.06.2014]. http://dx.doi.org/10.1111/j.1467-8551.2010.00693.x

[26] Kishore, S., "The Power of Incremental Innovation," Wired.com, 2013, [Accessed 13.06.2014].

[27] Tumati, P., "Types of Innovations." Go for Funding, 2013, [Accessed: 15.06.2014]

[28] Gilliard, M., "Radical Innovation," Innovation Creativity, 2014. [Accessed: 15.06.2014].

Emil William Thattakath received the Bachelor's degree in Biotechnology Engineering from the SRM University, Tamil Nadu, India. And is pursuing the Master's degree in Technology Management in Kaunas University of Technology, Kaunas, Lithuania. This paper is a representation of his Master Thesis. He is an Administrative Assistant with the International Relations Department of KUT.

E-mail: emil.thattakath@ktu.edu

Rūta Čiutienė received the Doctoral degree from ISM University of Management and Economics, Lithuania, in 2006. The topic of her doctoral dissertation was ,Coordination of Employees and Organizations Interests in Career Development". She is a Professor with the School of Economics and Business, Kaunas University of Technology. Since September 2013, she has been the coordinator of the Project Management Master programme; since 2012 - the manager of a scientific research group funded by the Institutional Scientific Research Programme „Challenges of Lithuanian economy's longterm competitiveness". The fields of her scientific interest are: project management, human resources management, human capital, career management problems.

E-mail: ruta.ciutiene@ktu.lt 